\title{
INFANTILE GLIOSARCOMA
}

\author{
José Roberto Tude Melo', André Luiz Pitanga Bastos de Souza², \\ Rodolfo Casimiro Reis ${ }^{2}$, Marco Antônio Cardoso de Almeida ${ }^{3}$
}

Since the first reports published by Stroebe in 1895 , more than 100 cases of gliosarcoma have been reported, eight of which were in children'. Gliosarcoma accounts for 1.8 to $8 \%$ of all glioblastomas'. It is classified by the World Health Organization (WHO) as a grade IV tumor and is composed of malignant glial and mesenchymal tissue ${ }^{2-4}$. This tumor affects supratentorial regions, particularly the peripheral region of the temporal lobe, normally near the falx cerebri and diploe. It usually affects the adult population in the fifth to sixth decades of life, males being more frequently affected than females (male/female ratio 1.8:1) ${ }^{1,2,5}$. Sixty percent of patients experience paresis and $55 \%$ report headaches ${ }^{6}$. At computed tomography (CT), the appearance of the tumor is extremely variable; however, the imaging presentation is generally of a heterogeneous hyperdense lesion with intense peritumoral edema and necrotic areas. There have been some reports of cases of hypodense images in which the histological diagnosis was gliosarcoma. In children, the tumor may appear as an extensive cystic mass. It is important to differentiate gliosarcoma from meningioma in which there is more homogeneity with contrast enhancement and less edema ${ }^{1,7}$. Magnetic resonance imaging (MRI) shows a hyperintense lesion with irregular contrast enhancement at T1. T2 sequence appears as an isointense lesion? ${ }^{7}$. Histologically, the tumor is composed of areas of mesenchymal and glial differentiation. The glial component is composed of pleomorphic astrocytic cells that are immunopositive to glial fibrillary acidic protein (GFAP), proliferative endothelium and occasional sites of necrosis. The sarcomatous component is comprised of uniform spindle cells arranged in fascicles between reticulin fibers. Vimentin and S-100 are used as markers of connective tissue $^{8}$. The pathogenesis of gliosarcoma is still controversial and some authors sustain the idea of a sarcomatous transformation of the endothelial cells of glioblastomas, while others affirm that the sarcomatous component originates from vascular smooth muscle cells, fibro- blasts, pericytes and undifferentiated mesenchymal cells. However, the most acceptable theory, based on genetic studies, is the dedifferentiation of glial cells into mesenchymal ones ${ }^{8,9}$. Prognosis is similar to that of most glioblastomas, with a mean survival time of 6 to 14.8 months following diagnosis, although one case has been reported in the literature in which the patient had a 22-year interval without recurrences ${ }^{8}$. The mean interval between recurrences ranges from 53.5 to 62 weeks ${ }^{9}$. The predominance of the sarcomatous component is associated with a better prognosis and a greater recurrence-free interval ${ }^{9}$. Some authors claim that metastases are rare, while others report that they occur in up to one third of cases, principally in the lungs, pleura, lymph nodes, bone marrow, liver, spinal cord, kidney and peripancreatic areas ${ }^{6,7}$. The role of chemo- and radiotherapy in the treatment of gliosarcoma remains to be defined, although some authors believe that these adjuvant forms of therapy are important, particularly in the case of children ${ }^{1,8}$.

We describe an infantile case of gliosarcoma after the authorization of the parents.

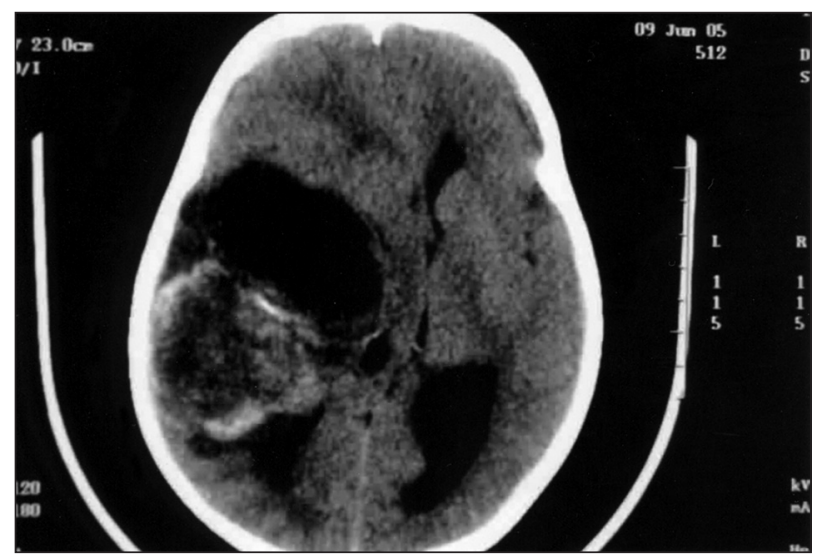

Fig 1. Computed tomography displaying a bulk tumor in right temporal lobe, with peripheral enhancement after contrast medium injection (axial view).

\section{GLIOSARCOMA INFANTIL}

Complexo Hospitalar Universitário Professor Edgard Santos da Universidade Federal da Bahia (HUPES-UFBA) e Hospital São Rafael (HSR), Salvador BA, Brazil: ${ }^{1}$ Neurocirurgião, Doutorando em Medicina pela UFBA; ${ }^{2}$ Acadêmico da Faculdade de Medicina da UFBA; ${ }^{3}$ Chefe do Serviço de Anatomia Patológica do HSR.

Received 9 August 2007, received in final form 4 October 2007. Accepted 29 November 2007.

Dr. José Roberto Tude Melo - HUPES/UFBA - Rua Augusto Viana sn $/ 2^{\circ}$ andar - 40110-060 Salvador BA - Brasil. E-mail: jmelo@hupes.ufba.br 


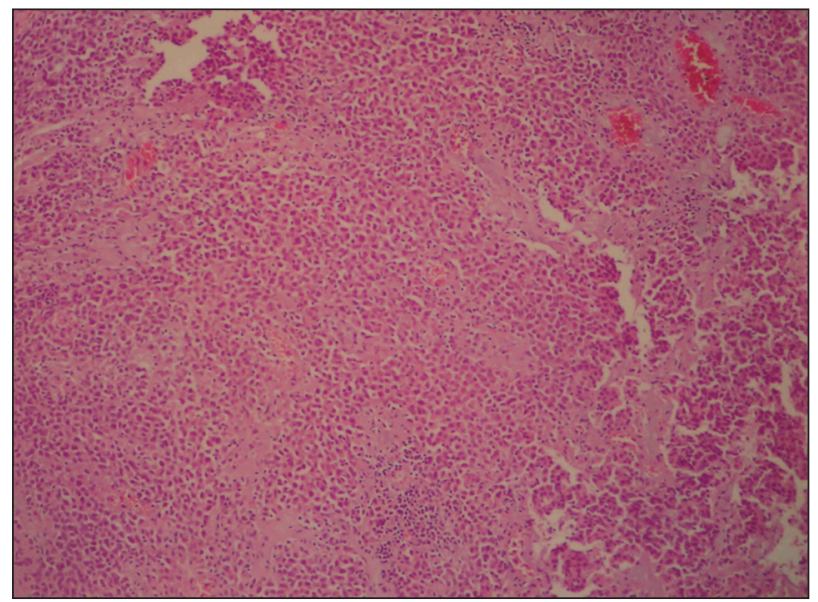

Fig 2. Photomicrografy displaying the biphasic nature of gliosarco$m a(H E 400 x)$.

\section{CASE}

A 4 year-old-boy was taken to hospital with complaints of a rapidly worsening headache, generalized seizures and left hemiparesis, principally in the face and arm. Computed tomography (CT) showed a bulk tumor in the right temporal lobe, with irregular contrast enhancement (Fig 1). A radical resection of the neoplasia was performed, and the histopathological diagnosis was gliosarcoma (Fig 2). Adjuvant chemo- and radiotherapy was recommended but was not adhered to by the patient's guardians due to the poor socioeconomic conditions of the family. The child was brought back to the hospital three months later at which time his level of consciousness had decreased and he was suffering from seizures. He died five days after the second neurosurgical intervention.

\section{DISCUSSION}

There are few reports in the literature of gliosarcoma in children. Of the 145 cases of infantile neoplasia that have undergone surgery in our institute, this has been the only case of gliosarcoma.

No discrepancy was found between the clinical and imaging presentations, in disagreement with previous reports in the literature. Imaging scans provided us with a heterogenous temporal image with irregular enhancement under endovenous contrast, which was in agreement with descriptions published in previous reports.

There was a 3-month overall survival in this case, principally due to the discontinuation of adjuvant therapy as a result of the family's socioeconomic limitations. However, it is well-known that infantile gliosarcoma sometimes responds to adjuvant chemo- or radiotherapy ${ }^{10,11}$.

\section{REFERENCES}

1. Okami N, Kawamata T, Kubo O. Yamane F, Kawamura H, Hori T. Infantile gliosarcoma: a case and a review of the literature. Child's Nerv Syst 2002;18:351-355.

2. Ohgaki H, Biernat W, Reis R, Hegi M, Kleihues P. Gliosarcoma. In Kleihues P, Cavenee WK (eds). Pathology and genetics of tumors of the nervous system. Lyon: IARC Press 2000:42-44.

3. Goldstein SJ, Young B, Markesberry WR. Congenital malignant gliosarcoma. Am J Neuroradiol 1981;2:475-476.

4. Parekh HC, O'Donovan DG, Sharma RR, Keogh AJ. Primary cerebral gliosarcoma: report of 17 cases. Br J Neurosurg 1995;9:171-178.

5. Meis JM, Martz KL, Nelson JS. Mixed glioblastoma multiforme and sarcoma: a clinicopathologic study of 26 Radiation Therapy Oncology Group cases. Cancer 1991;67:2342-2349.

6. Witwer BP, Salamat MS, Resnick DK. Gliosarcoma metastatic to the cervical spinal cord: case report and review of the literature. Surg Neurol 2000;54:373-379.

7. Moreira RK, Koppe D, Zignani J, et al. Gliossarcoma de tronco cerebral em paciente pediátrico: relato de caso. Radiol Bras 2004;37:61-63.

8. Winkler PA, Büttner A, Tomezzoli A, Weis S. Histologically repeatedly confirmed gliosarcoma with long survival: review of the literature and report of a case. Acta Neurochir (Wien) 2000;142:91-95.

9. Salvati M, Caroli1 E, Raco A. Gliosarcomas: analysis of 11 cases do two subtypes exist? J Neuro Oncol 2005;74:59-63.

10. Ono N, Nakamura M, Inoue HK, Tamura M, Murata M. Congenital gliosarcoma; so-called sarcoglioma. Childs Nerv Syst 1990;6:416-420.

11. Radkowski MA, Naidich TP, Tomita T, Byrd SE, McLone DG. Neonatal brain tumors: CT and MR findings. J Comput Assist Tomogr 1988; 12:10-20. 